\title{
VÄITÖKSET
}

\section{Wellness on aikaamme leimaava hyvinvointisuuntaus}

Yhteiskunnallisen muutoksen myötä myös käsitys hyvinvointia tuottavasta elämäntyylistä on jatkuvassa muutoksessa. Muutamia vuosikymmeniä takaperin olisimme todennäköisesti nauraneet ajatukselle siitä, että päivittäisten askelmäärien mittaaminen tai pienten meditaatiohetkien ujuttaminen työpäivän lomaan olisivat jollain tapaa tarpeellisia, saati välttämättömiä hyvinvointimme näkökulmasta. Nyt erilaiset kehon ja mielen hyvinvointia tukevat yksilölliset tekniikat ja teknologiat ovat tulleet osaksi arkista itsehoitoa.

Olitpa sitten opiskelija, työssäkäyvä tai eläkeläinen, on sosiaalisesti hyväksyttävää käyttää aikaa oman hyvinvoinnin pohtimiseen ja itselle sopivien hyvinvointirutiinien rakentamiseen. Voidaan jopa todeta, että hyvinvoinnistaan laaja-alaisesti kiinnostunut ja sitä alati tarkkaileva ja kehittävä yksilö on tämän päivän hyvinvointikansalaisen ihannekuva.

Vai olisiko oikeampaa sanoa wellness-kansalaisen ihannekuva?

Väitöskirjassani lähestyn nykymuotoista hyvinvointikulttuuria wellness-käsitteen kautta. Vuosituhannen vaihteen jälkeen wellness ja siihen kytkeytyvä elämyksellinen hyvinvointikulutus eli wellness-kulutus ovat nousseet hyvinvointikeskustelun keskiöön etenkin vauraissa länsimaissa.

Tutkimuksessani määrittelen wellneksen hyvinvointisuuntaukseksi, joka korostaa yksilön vastuuta, valveutuneisuutta ja yksilöllisiä elämäntyylivalintoja henkilökohtaisen hyvinvoinnin edistämisessä. Wellness-käsitteellä en siis viittaa mihinkään todennettavissa olevaan keholliseen olotilaan tai yksittäiseen hyvin- vointibrändiin vaan ilmiökenttään, joka on vallannut sijaa yhteiskunnassa monin eri tavoin.

Nyky-yhteiskuntaa voidaan kutsua kulutusyhteiskunnaksi, jossa keskeiset sosiaaliset käytännöt ja käsitykset kietoutuvat tavalla tai toisella kulutukseen. Kulutus on myös keskeinen osa wellness-ilmiötä.Joogastudiot, lisäravinteet, hyvinvointivalmennukset, aktiivisuusrannekkeet ja kylpylät, noin muutaman mainitakseni, ovat osa kaupallista wellnesstä. Myös hyvinvointiaiheiset blogit, tosi-tv-formaatit ja monet muut mediasisällöt tarjoavat esimerkkejä erilaisista itsestä huolehtimisen tavoista ja omalta osaltaan kannustavat wellness-kulutuksen pariin.

Wellness ei kuitenkaan ole pelkkä kuluttajailmiö tai ohimenevä kulutustrendi. Niin työelämässä, koulutuksessa kuin päätöksenteossa painotetaan keinoja, joilla ihmiset voisivat itse ratkoa omia terveyteen ja hyvinvointiin liittyviä haasteitaan. Puhutaan terveystietoisuuden lisäämisestä, arjen hallinnasta ja hyvinvointia tukevista elintavoista. Kokonaisvaltaiseen itsehoivaan kannustava eetos ulottuu siis varsin syvälle nyky-yhteiskunnan rakenteisiin.

Wellness-ilmiön nousun taustalla voidaan nähdä moninaisia yhteiskunnallisia kehityskulkuja. Niin lääketieteessä, teollisuudessa kuin teknologiassa on otettu valtavia edistysaskelia, jotka ovat mahdollistaneet elintason nousun ja toimintakykyisten elinvuosien lisääntymisen. Yhteiskunnan hyvinvointihaasteiden ollessa entistä monisyisempiä ja vaikeammin hallittavia ihmisiltä myös odotetaan enemmän vastuunottoa omasta hyvinvoinnista sekä kykyä sopeutua nopeasti muuttuviin olosuhteisiin. 
Niin paradoksaalista kuin se onkin, hyvinvoinnin kasvu on taannut kasvualustan ilmiölle, jonka myötä hyvinvoinnin edistämisestä on tullut läpi elämän jatkuva tavoitteellinen projekti.

Vaikka kokemus hyvinvoinnista on subjektiivinen ja hyvinvointia edistetään henkilökohtaisten resurssien ja mieltymysten mukaisesti, valintoihimme ja kokemukseemme vaikuttavat myös yhteiskunnan normit ja rakenteet. Esimerkiksi eri ikäisiin ja eri elämänvaiheissa oleviin ihmisiin kohdistuu erilaisia odotuksia sen suhteen, miten heidän tulisi toimia itsehoivan saralla.

\section{Tutkimuksen näkökulma ja aineistot}

Väitöskirjani keskiössä ovat hyvinvointia ja itsehoivaa koskevat asenteet ja kulutuskäytännöt, joita olen tarkastellut pääasiassa ikääntymisen näkökulmasta. Kiinnostukseni on kohdistunut erityisesti siihen, miten tutkimushenkilöni hahmottavat hyvinvoinnin edistämisen ympärille muotoutuneita arjen käytäntöjään. Lisäksi olen pohtinut näiden yksilöllisten hyvinvointistrategioiden suhdetta ympäröivään kulttuuriin.

Väitöskirjani koostuu kolmesta osatutkimuksesta. Ensimmäinen osatutkimus pohjautuu suomalaisten kylpyläkävijöiden keskuudessa teetettyyn kyselytutkimukseen. Siinä tarkastelen hyvinvoinnin edistämiseen liittyviä asenteita ja kulutuskäytäntöjä sekä niiden yhteyttä vastaajien taustatietoihin, kuten esimerkiksi ikään, sukupuoleen ja koulutustasoon. Toisessa osatutkimuksessa syvennyn ryhmähaastatteluiden kautta myöhäiskeski-ikäisten näkemyksiin ja kokemuksiin itsehoivasta ja wellness-kulutuksesta. Kolmannessa osatutkimuksessa pureudun havainnointia ja yksilöhaastatteluja yhdistävän kenttätyön kautta holistisen itsehoivan saamiin merkityksiin osana eläkeläisten elämänvaihetta.

Kokonaisuutena väitöskirjani paikantuu sosiologisen kulutus- ja elämäntapatutkimuksen sekä ikä- ja elämänkulkututkimuksen leikkauskohtiin. Osin näkökulma on monitieteellinen, sillä ammennan väitöskirjassani myös terveystieteistä sekä vapaa-ajan ja matkailun tutkimuksesta. Tämä siitä syystä, että wellness-aiheista keskustelua on aiemmin käyty pääasiassa muualla kuin yhteiskuntatieteissä. Toki sosiologialla on tieteenalana ollut paljon sanottavaa kulutukseen ja terveyskäyttäytymiseen liittyvistä ideologisista ja moraalisista näkökohdista, mutta toistaiseksi wellness-käsite on pysynyt melko näkymättömänä näissä keskusteluissa.

Eräs väitöskirjani keskeisistä tavoitteista olikin kuroa yhteen hyvinvointiin, itsehoivaan ja hyvinvointikuluttamiseen kiinnittyviä monitieteisiä keskusteluja ja näin rikastuttaa myös sosiologista hyvinvointitutkimusta. Vaikka wellness-sana saattaa suomalaisen korvaan tuntua kömpelöltä anglismilta, osoittautui se toimivaksi käsitteelliseksi välineeksi näiden moninaisten näkökulmien yhteen saattamisessa.

\section{Hyvinvoinnin edistämisen uudet suunnat}

Wellness-ilmiön ytimessä voidaan nähdä muutos, jossa käsitys hyvinvoinnista on laajentunut terveyden edistämisen alueelta muille elämänalueille. Arkipuheessa hyvinvoinnin käsite rinnastetaan usein elämänlaadun ja elämäntyytyväisyyden käsitteisiin. Vastaavasti hyvinvoinnin edistäminen yhdistetään vahvasti itsehoivaan ja elämänhallintaan - toisin sanoen yksilöllisiin elämäntyylivalintoihin.

Väitöskirjassani argumentoin, että hyvinvointia lähestytään enenevissä määrin taitoperusteisesti. Ajatellaan, että hyvinvointi on jotain, missä yksilö voi kehittyä ja tulla taitavaksi. Tällainen ajattelu on monella tapaa ongelmallista mutta kasvattaa myös kysyntää henkilökohtaisen hyvinvoinnin edistämiseen tarkoitetuille tuotteille ja palveluille. Kulutusyhteiskunnassa olemme tottuneet luottamaan siihen, että elämän varrella kohtaamiimme haasteisiin löytyy asiantuntijan muotoilema ratkaisu, joka on ulottuvillamme rahaa vastaan tai yksinkertaisesti Googlen hakukonetta käyttämällä. 
Kulutuksen kontekstissa wellnekseen liitetään mielikuvia nuorekkaasta ja elinvoimaisesta olemuksesta. Tutkimukseni perusteella wellness-kulutuksessa ei kuitenkaan ole kyse ainoastaan ulkoisen olemuksen kohentamisesta tai terveyden edistämisestä. Kyse on pikemminkin niistä merkityksistä ja mielikuvista, joita hyvinvoinnin käsitteeseen ja itsehoivaan tänä päivänä liitetään. Kokonaisvaltaisen kehonboitotyön ajatellaan viestivän paitsi kehollisesta hyvinvoinnista myös muista nyky-yhteiskunnassa korkealle arvotetuista ominaisuuksista, kuten tehokkuudesta ja hyvästä elämänhallinnasta.

Niin ikään wellness-elämäntyyli on merkittävä sosiaalisen erottelun mekanismi. Kun erilaiset kulutushyödykkeet ovat tulleet yhä suuremman kansanosan ulottuville, materiaalisen kulutuksen sijaan omia arvoja, sosioekonomista statusta ja elämäntyyliä tehdään näkyväksi itseä ja omaa kehoa hoitamalla, kehittämällä ja muokkaamalla.

Tämä ei kuitenkaan vähennä wellness-kulutuksen merkitystä nautinnollisena ja elämyksellisenä kulutustyylinä. Wellness-markkinoilla lupaukset hyvästä olosta, onnellisuudesta ja menestyksestä näyttäisivät kietoutuvan itselle sopivien hyvinvointirutiinien rakentamiseen ja elämysten etsintään. Lienee selvää, että tällainen kulutustyyli puhuttelee voimakkaimmin suhteellisen hyvin toimeentulevia ja jo valmiiksi hyvinvoivia.

\section{Wellness-ilmiö osana muuttuvaa ikääntymisen maisemaa}

Tutkimukseni keskeiset johtopäätökset liittyvät siihen, miten wellness näyttäytyy osana muuttuvaa ikääntymisen maisemaa. Keskeisin muutos lienee siinä, että varhaisvanhuudessa tai niin kutsutussa kolmannessa iässä vietetään tätä nykyä pidempi ajanjakso kuin esimerkiksi varhaisaikuisuudessa. Tämän päivän ikäihmiset ovat myös keskimäärin aiempia sukupolvia terveempiä ja vauraampia, mikä on muokannut heidän elämäntyylejään aktiivisempaan suuntaan.

Myös vallitsevat - ikääntyvien aktiivisuutta ja tuottavuutta painottavat - ikääntymisdiskurssit tuottavat käsitystä siitä, että työelämän jälkeen odottaa elämänvaihe, jossa on enemmän aikaa itselle ja omille mielenkiinnonkohteille. Samalla nämä näkökulmat liittävät vanhenemisen vahvasti osaksi yksilön omia elämänstrategisia valintoja.

Ikääntymisprosessi,johon vääjäämättömänä osana kuuluu kehon toimintakyvyn asteittainen heikentyminen, ei kuitenkaan itsestään selvästi istu itseään alati kehittävän ja hyvinvointiaan optimoivan wellness-kansalaisen ihannekuvaan. Tästä syystä ikääntyminen tarjoaa mielenkiintoisen analyyttisen linssin wellness-ilmiön tarkastelulle.

Haastateltavieni kokemuksissa ikääntyminen näyttäytyy prosessina, johon liittyy luopumista ja sopeutumista mutta myös uusien mahdollisuuksien avautumista. Sekä myöhäiskeskiikäisten että eläkeläisten kohdalla aineistosta nousee esiin kokemus kehon asteittaisesta ikääntymisestä ja sen myötä voimistunut halu etsiä keinoja, joiden avulla ylläpitää fyysistä ja henkistä kuntoisuutta. Tämä tarve heijastaa ikääntyvien omia toiveita mutta myös yhteiskunnassa yleisesti vallitsevia ikääntymisnormeja.

Kulutusyhteiskunnassa vanhenemiseen usein suhtaudutaan sarjana toisiaan seuraavia haasteita, joita voi hallita kulutuksen keinoin. Wellness-markkinoilla varttuneet kuluttajat esitetäänkin usein terveyskuluttajina tai ikääntymisen merkeistä huolestuneina Anti aging -kuluttajina, ei niinkään hyvää oloa ja uusia kokemuksia etsivinä wellness-kuluttajina.

Tutkimustulosteni perusteella wellness-kulutuksen saamat merkitykset varttuneiden $\mathrm{ku}-$ luttajien kokemuksissa ovat kuitenkin varsin moninaiset. Fyysisten tekijöiden lisäksi wellness-kulutuksen pariin kannustavat elämänvaiheen muutokset. Esimerkiksi eläkkeelle jäänti näkyy aineistossa merkittävänä elämänkulun 
taitekohtana, joka suuntaa huomiota enemmän itseen ja omaan hyvinvointiin. Itsehoiva on yksi keino rakentaa ja rytmittää työelämän jälkeistä elämää sekä lunastaa varhaisvanhuuteen kohdistuvat toimeliaisuuden odotukset.

Myöhäiskeski-ikäisten pohdinnat hyvinvoinnin edistämisestä kietoutuvat monilta osin työssä ja arjessa jaksamiseen nykyisessä elämänvaiheessa. Tämän lisäksi niissä näkyvät omaa vanhenemista koskevat toiveet ja odotukset. Oman hyvinvoinnin äärelle pysähtymisen ja hyvinvointirutiinien päivittämisen kautta etsitään helpotusta arjen kiireeseen, mutta samalla myös suunnataan huomiota siihen, minkälaista elämän toivotaan olevan, kun työelämän velvoitteet vähentyvät. Stressin hallinta, itsen kokonaisvaltainen kehittäminen sekä kiinnostus hyvinvointielämyksiä kohtaan ovat korostetusti esillä myöhäiskeski-ikäisten haastateltavieni kokemuksissa.

Haastattelemieni eläkeläisten keskuudessa puolestaan korostuu wellness-kulutuksen merkitys voimauttavana ja virkistävänä osana eläkeläisen elämää. Elämänvaiheessa, jossa suurelta osin muut kuin työ- ja perhevelvoitteet määrittävät arjen kulkua, hyvinvoinnin edistämiseen liittyvistä rutiineista ja kulutuskäytännöistä voi muodostua tärkeitä arkea rytmittäviä tekijöitä. Vaikka terveys ja toimintakyky ovat vahvasti esillä eläkeläisten hyvinvointia koskevissa pohdinnoissa, wellness-kulutuksesta ei haeta vain terveyshyötyjä vaan kokonaisvaltaista mielenvireyttä. Aineistoni valossa wellness-kulutuksen merkityksellisyys eläkeläisten kokemuksissa kiinnittyi pääasiassa sosiaaliseen kanssakäymiseen sekä osallisuuden ja pystyvyyden kokemuksiin. Myös mahdollisuus omannäköiseen itsehoivaan - itsen hemmottelua unohtamatta - näytti vahvistavan koettua hyvinvointia.

Ikääntymisen yhteydessä itsehoiva koetaan tärkeäksi myös siksi, että elämän halutaan säilyvän omatoimisena ja omaehtoisena mahdollisimman pitkään. Voidaankin ajatella, että nykyaikana, jolloin ihmisen elämänkulku ei ole enää niin vahvasti sidottu kronologiseen ikään ja yhteiskunnan kollektiivisiin rakenteisiin, itsehoiva ja kehokeskeinen kulutus toimivat eräänlaisina oman elämänkulun suunnittelun välineinä. Itsen hoivaamisen tavat muuttavat muotoaan elämänkulun varrella, mutta tarve omaan hyvinvointiin vaikuttavien tekijöiden ymmärtämiselle ja hyvinvoinnin kehittämiselle nähdään elämän mittaisena.

\section{Wellness-ilmiön monet kasvot}

Sitä, millaiseksi elämä lopulta muotoutuu, ohjaavat kuitenkin suurelta osin myös geenit ja sattuma. Itsehoiva ja wellness-kulutus voidaan nähdä osatekijöinä positiivisten ikääntymiskokemusten saavuttamisessa, mutta ne eivät missään nimessä ohjaa vanhenemisprosessia tai määritä "onnistunutta" ikääntymistä. Ylipäätään onnistumisesta tai paremmuudesta puhuminen ikääntymisen tai hyvinvoinnin yhteydessä on jokseenkin tarpeetonta.

Jos, ja enenevissä määrin, kun hyvinvointi ja elämässä menestyminen palautetaan yksilön taitoihin ja valintoihin, lakaistaan vain näkyvistä monia yksilön hyvinvointiin vaikuttavia sosiokulttuurisia ja sosioekonomisia tekijöitä.

On tärkeää huomata, ettei henkilökohtaisen hyvinvoinnin edistäminen ole kaikille mahdollista samassa muodossa. Kaikilla ei ole samanlaisia taloudellisia ja sosiaalisia resursseja omaan elämäntilanteeseen sopivan itsehoivan toteuttamiseen. Näin ollen hyvinvoinnin kaupallistuminen yhdessä yksilön taitoihin nojaavan hyvinvointieetoksen kanssa luo elämyksellistä hyvinvoinnin optimoinnin areenaa heille, joilla jo on riittävät resurssit hyvinvoinnin kokonaisvaltaiseen edistämiseen.

Ongelma ei niinkään ole tuotteiden tai palveluiden kalleus, sillä joogamatka, kylpylähoidot tai henkilökohtainen valmentaja tuskin ovat kenenkään hyvinvoinnin kannalta elinehto. Sen sijaan hyvinvoinnin edistämiseen liittyvä eriarvoisuus ilmenee valinnanmahdollisuuksien runsaudessa tai vastaavasti niiden kapeudessa. 
Harva on eri mieltä siitä, etteikö omasta terveydestä ja hyvinvoinnista huolehtiminen olisi tärkeää. Kuitenkin ajatus siitä, että yksilön tulisi taukoamatta voida hyvin ja suoriutua elämän mittaisesta hyvinvointiprojektistaan omin avuin, voi myös tuottaa ahdistuksen, riittämättömyyden ja välinpitämättömyyden tunteita. Yhtenä ääripäänä on myös tilanne, jossa oman hyvinvoinnin tarkkailusta ja hienosäädöstä tulee niin pakonomaista, että siitä muotoutuu terveydelle haitallinen addiktio.

Wellness-ilmiö kätkee siis sisälleen monia sosiologisesti äärimmäisen mielenkiintoisia ristiriitaisuuksia, joita väitöskirjani empiirisen aineiston kautta pääsin kuopaisemaan vain pintapuolisesti. Tutkimushenkilöideni kokemuksissa korostuvat yksilölliset valinnat, nautinnolliset elämykset sekä kokonaisvaltainen kiinnostus oman hyvinvoinnin edistämiseen. Positiivista hyvinvointipuhetta sävyttävät kuitenkin kokemukset nyky-yhteiskunnan hektisyydestä, suorituskeskeisyydestä ja arjen kuormittavuudesta, ja niiden myötä huoli omasta jaksamisesta ja pärjäämisestä. Kyselyaineistossa näkyy myös viitteitä wellness-ilmiön eriarvoistavista vaikutuksista.

Ei ole ollenkaan yhdentekevää, millaiseksi hyvinvoinnin käsite yhteiskunnallisessa keskustelussa muotoutuu. Vaikka wellness itse- hoivaan kannustavana hyvinvointisuuntauksena osittain vastaa aikamme hyvinvointihaasteisiin, on se myös omiaan syventämään hyvinvointieroja yhteiskunnassa. Tästä syystä olisi tärkeää tunnistaa eri ikäisten ja eri elämänvaiheissa olevien ihmisten toiveita ja tarpeita itsehoivaan liittyen ja tukea niitä eri tavoin. On myös kaikkien hyvinvoinnin kannalta eduksi vahvistaa sellaista hyvinvointikulttuuria, joka ei saa tuntemaan häpeää epäterveellisiksi leimatuista elämäntavoista tai siitä,jos ei kykene saavuttamaan sisäistä harmoniaa meditaatioapplikaation tarjoamasta avusta huolimatta.

Lopuksi on myös hyvä todeta, että vaikka aikaamme leimaa tietynlainen iättömyyden ihanne - ajatus siitä, että mikä tahansa on mahdollista missä iässä ja elämänvaiheessa tahansa - elinajanodotteen loputonta venyttämistä ei edes kasvavilta wellness-markkinoilta saa ostettua.

\section{Veera Koskinen, YTT}

veera.koskinen@helsinki.fi

Sosiologian alaan kuuluva väitöskirja "Building skills for lifelong wellness: An empirical study on the wellness-oriented lifestyle" tarkastettiin Jyväskylän yliopistossa 21.8.2020.

\section{Kirjallisuutta}

Cederström C, Spicer A. The wellness syndrome. John Wiley \& Sons, 2015.

Conrad P. Wellness as virtue: morality and the pursuit of health. Cult Med Psych 1994;18(3):385401. https://doi.org/10.1007/BF01379232

Crawford R. Health as a meaningful social practice. Health 2006;10(4):401-20. https://doi.org/10.1177/1363459306067310

Gilleard CJ, Higgs P. Cultures of ageing: self, citizen, and the body. Pearson Education, 2000.

Katz S. Cultural aging: life course, lifestyle, and senior worlds. Peterborough: Broadview, 2005.

Keller M, Halkier B, Wilska TA, Truninger M, ed. Routledge handbook on consumption. Taylor \& Francis, 2017.

Koskinen, V. Spa tourism as a part of ageing well. International Journal of Spa and Wellness 2019;2(1):18-34. https://doi.org/10.1080/24721735.2019.1668673

Koskinen V. Building skills for lifelong wellness: an empirical study on the wellness-oriented lifestyle. JYU dissertations, 2020.

Koskinen V, Wilska TA. Identifying and understanding spa tourists' wellness attitudes. Scand J Hosp Tour 2019;19(3):259-77. https://doi.org/10.1080/15022250.2018.1467276

Koskinen V, Ylilahti M, Wilska TA. "Healthy to heaven": middle-agers looking ahead in the context of wellness consumption. J Aging Stud 2017;40:36-43. https://doi.org/10.1016/j.jaging.2016.12.006 
Lumme-Sandt K. Images of ageing in a 50+ magazine. J Aging Stud 2011;25(1):45-51. https://doi.org/10.1016/j.jaging.2010.08.013

Pack R, Hand C, Rudman DL, Huot S. Governing the ageing body: explicating the negotiation of 'positive' ageing in daily life. Ageing Soc 2018;39(9)2085-108.

https://doi.org/10.1017/S0144686X18000442
Sassatelli R. Fitness culture: gyms and the commercialisation of discipline and fun. Basingstoke: Palgrave Macmillan, 2010.

Smith M, Puczkó L. Health, tourism and hospitality: spas, wellness and medical travel. London: Routledge, 2014.

Smith Maguire J. Fit for consumption: sociology and the business of fitness. Routledge, 2007. 